\title{
A Performance Test Device for Thermostat Dehumidifier Based on Air Enthalpy Contrast Method of Wind Tunnel
}

\author{
Haiding Zhang ${ }^{1, a)}$,Yaqi $\mathrm{Li}^{1, \mathrm{~b})}$,Donghai Zhu ${ }^{2, \mathrm{c})}$ andYuan $\mathrm{Liu}^{3, \mathrm{~d})}$ \\ ${ }^{1}$ Xi'an institute of High Tech Research, Xi'an, 710025, China. \\ ${ }^{2}$ Xi'an institute of High Tech Research, Xi'an, 710025, China. \\ ${ }^{3}$ Xi'an institute of High Tech Research, Xi'an, 710025, China. \\ a)295006978@qq.com, ${ }^{\mathrm{c})} 15594973233 @ 163 . c o m,{ }^{\mathrm{d}}$ 675761355@qq.com
}

Keywords: Thermostat dehumidifier, Air enthalpy, Wind tunnel

\begin{abstract}
In order to guide the application of thermostat dehumidifier products, a performance test device based on air enthalpy contrast method of wind tunnel was designed, the hardware technical requirement and software function are introduced. Byte sting the KFRS-20ZM/AS dehumidifier, the relationship between the amount of desiccant and heat transfer, the amount of unit power and the input power are analyzed, finally the reliability of the test device is verified from the performance test results.
\end{abstract}

\section{INTRODUCTION}

With the development of science and technology, The requirements of the temperature and humidity on the working environment a variety of mechanical and electrical equipment are getting higher and higher, So the thermostat dehumidifier is widely used. Especially for underground works, the performance of the thermostat dehumidifier directly affect the safe operation of the equipment, the time of material storage and the living conditions of the operators. In actual use, Performance degradation is due to the dehumidifier is running in non-standard conditions, and does not meeting the factory design in most cases, ${ }^{[1]}$ Therefore, the dehumidifier product performance testing and research work under different conditions of work performance is particularly important.

At present, the dehumidifier performance test device research has been a great degree of development, many well-known manufacturers and research departments have established a related experimental platform, Such as the traditional weighing method experimental system, unit air conditioner performance laboratory, Guangzhou Chun lan company established a small air conditioner Enthalpy Contrast laboratory. ${ }^{[2][3]}$ However, there are still two problems: 1 ) Most of the departments to establish the laboratory are for air conditioning products, the dehumidifier performance parameters of the measurement accuracy is not high, such as the measurement of air flow with a simple air flow meter (pitot tube, balloon anemometer, wind speed sensor ) Or the nozzle standard used is not sufficient; (2) The amount of desiccant dehumidifier measurement using weighing method, time-consuming, can not be dynamic monitoring ${ }^{[4]}$. According to the existing national standard GB/T19411-2003 "dehumidifier"[5] and GB/T17758-2010 "unit type air conditioner" ${ }^{[6]}$, based on the traditional weighing method dehumidifier performance testing system, The dehumidifier performance test device of Air Enthalpy Contrast method is used to test the performance parameters of the amount of desiccant and heat transfer, the amount of unit power and the input power

\section{TEST PRINCIPLE AND TECHNICAL REQUIREMENTS}

\subsection{Test principle}

Air Enthalpy Contrast Method on the performance of temperature and Thermostat Dehumidifier test principle is: When the operating conditions of the dehumidifying unit to be tested are stable, the testing device calculates the enthalpy difference before and after dehumidification of the dehumidifier through the measurement of the dry and wet bulb temperature and the air flow rate of 
the inlet and outlet air of the dehumidifier, and the cooling capacity is multiplied by the air volume. Including the sensible heat and latent heat, in which the latent heat generated by the water vapor phase transition in the humid air is the dehumidification amount.

Cooling capacity is calculated as:

$$
Q=G_{a}\left(h_{a 1}-h_{a 2}\right) /\left[\left(1+d_{n}\right) v_{n}\right]
$$

Through the look-up table in the enthalpy table can be obtained by the corresponding moisture content $h$ and enthalpy $d$, but the efficiency is not high,it can be calculated as follows:

$$
\begin{aligned}
& d=0.62198 \frac{P_{V}}{B-P_{V}} \\
& h=1.005 t+d(2501+1.86 t)
\end{aligned}
$$

Where: $G_{a}$ is the air flow; $P_{v}$ is the wet air vapor pressure, can be calculated from the dry and wet bulb temperature; $B$ is the standard atmospheric pressure; $t$ is the dry bulb temperature.

Dehumidification capacity (latent heat) is calculated as:

$$
D=G_{a}\left(W_{1}-W_{2}\right) / v_{n}\left(1+W_{n}\right)
$$

Where: $D$ is the dehumidifier calculated by the Enthalpy Contrast method, $W$ is the absolute humidity, $v$ is the specific volume of air, subscripts 1 and 2 are the inlet and outlet of the humidified air of the measured dehumidifier, respectively, and the subscript $n$ is the wind tunnel nozzle position

For the dehumidification efficiency evaluation index SMER (Specific Moisture Extraction Rate),in the current national standard "dehumidifier" (GB/T19411-2003) and "new air dehumidifier" (GB / T20109-2006) ${ }^{[7]}$ Definitions are given, but there are no clear requirements for energy efficiency standards

$$
\text { SMER }=\frac{D}{P}
$$

Among them, $\mathrm{P}$ is the dehumidifier input power, including the compressor input power and fan power.

According to the relevant national standard design aperformance test device for thermostat dehumidifier based on air enthalpy contrast method of wind tunnel, to create a constant temperature and humidity environment, while ensuring a stable air supply parameters and the environment closed to prevent enthalpy contrast room air temperature and humidity uneven, wind speed unstable, heat leakage phenomena and so on, to ensure the accuracy of the experiment.The schematic diagram of the test device is shown in Fig.1.

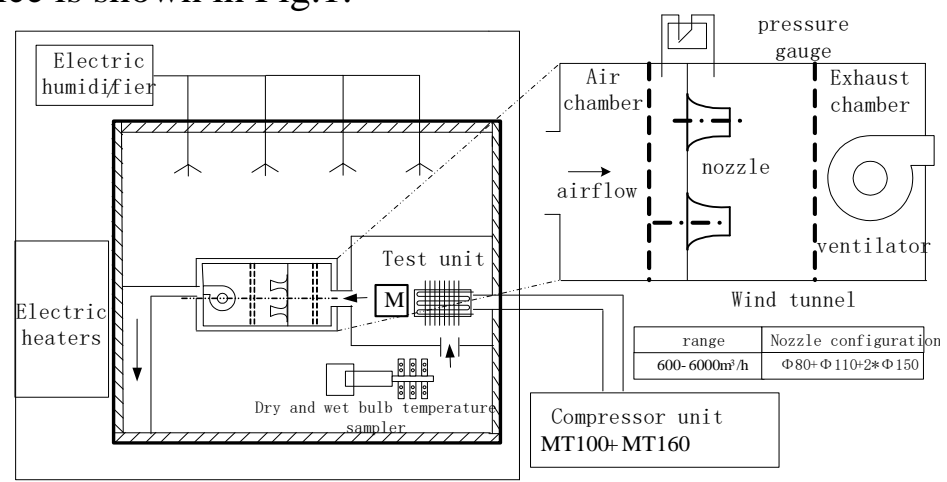

FIGURE 1.Schematic diagram of the test device 


\subsection{Test equipment}

The establishment of enthalpy contrast dehumidifier performance test device is divided into four parts: Refrigeration equipment, The control room, the enthalpy contrast indoor side and the enthalpy contrast outside the room.,including air handling systems and prototype test systems. Air handling systems include air handling units (AHU), evaporator coils, humidifiers and heaters. AHU is mainly used for conveying, mixing, heating, cooling, dehumidifying and humidifying the air inside the test room, thus creating a certain temperature and humidity environment. The humidification capacity of the auxiliary humidification equipment is controlled by the electrode humidifier to achieve isothermal humidification. The prototype test system is mainly to measure air volume, cooling capacity and power consumption of the prototype, including air sampling device, air flow measuring device and electric quantity measuring device. The air sampling device is used for uniformly sampling the air temperature and humidity of the test room, which comprises a sampling box, a sampling pipe and a sampling harrow with a small hole; the air flow measuring device is a "wind tunnel", which is composed of an air inlet chamber, nozzle, exhaust chamber and pressure gauge; the electric quantity measuring device is used for accurately measuring the voltage, current, power and other parameters of the prototype, and is mainly composed of a transformer.

Wind tunnel air enthalpy contrast method needs to measure the physical quantity, including wet and dry bulb temperature and air flow, air measurement sampling device is shown in Fig.2. The temperature and humidity are measured by temperature sampler. The measurement accuracy depends on the accuracy of the temperature sensor and the signal acquisition. It is affected by the platinum resistance pairing, the uniformity of the temperature field and the flow velocity of the air at the time of sampling.As the wet bulb temperature havea greater impact on the measurement of air enthalpy, the wet bulb temperature measurement must be in accordance with the requirements wrapped with wet gauze platinum resistance, while the wind speed is too high to dry gauze, so the sampling wind speed can not be too high, If the wind speed is too low will have a significant impact on relative humidity, combined with GB/T6999-2010"Relative humidity tables for environmental test " comprehensive consideration, in general, the wind speed in the $4-5 \mathrm{~m} / \mathrm{s}$ more reasonable ${ }^{[8]}$. In addition, the indoor side of the rake between the sampling environment should be placed in the appropriate location, the general distance from the prototype air outlet $0.12-0.16 \mathrm{~m}$.

Air flow through the high-precision measurement of the wind tunnel to calculate, the diameter of the nozzle has a great influence on the measurement accuracy, the measurement of static pressure difference and air density before and after the nozzle will also directly affect the accuracy of the calculation. The air volume measurement capability of the test device is $600-6000 \mathrm{~m}^{3} / \mathrm{h}$, the nozzle specification is $\Phi 80+\Phi 110+2 * \Phi 150$, the air volume is $9600 \mathrm{~m}^{3} / \mathrm{h}$, and the outlet static pressure is $1800 \mathrm{~Pa}$. In the actual assembly, in order to ensure that all the wind through the sample to be tested into the wind tunnel to connect the dehumidifier and wind tunnel closely.

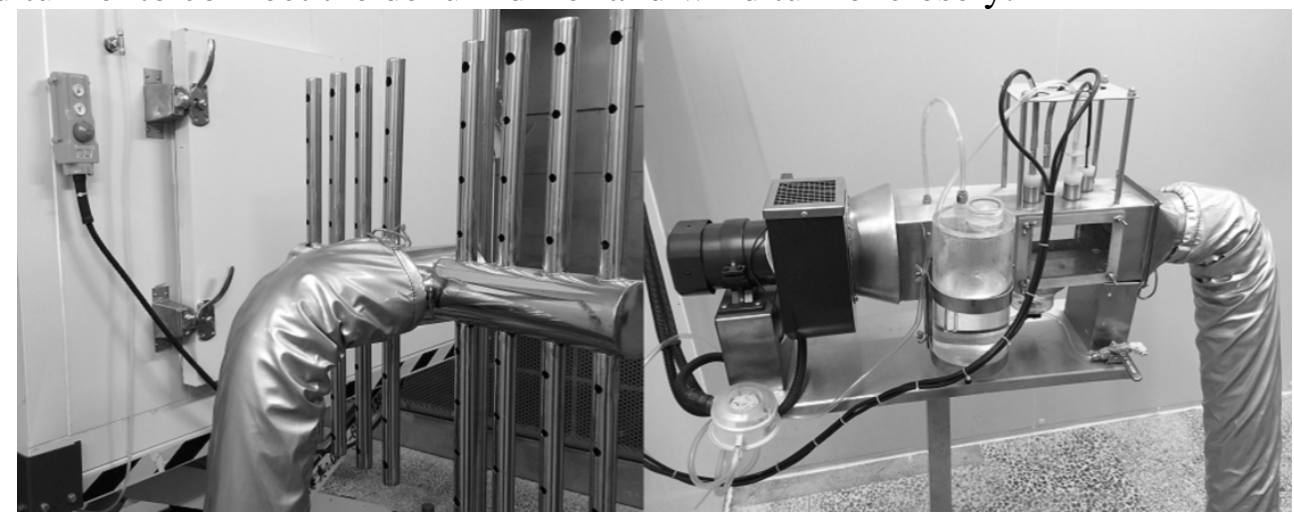

FIGURE 2.Air measurement sampling device

\section{3 related technical requirements}

Air re-treatment devices are mainly electric heaters, electric humidifiers and fans and so on. Electric heater with adjustable control, the control power of $48 \mathrm{~kW}$, according to the conditions 
required to adjust; electric humidifier rated power of $40 \mathrm{~kW}$, the maximum steam humidification capacity of $60 \mathrm{~kg} / \mathrm{h}$; fan air volume can reach $12000 \mathrm{~m}^{3} / \mathrm{h}$. The adiabaticity of the unit has a great impact on the measurement accuracy of the measuring device. It adopts the assembled plate polyurethane foam, the panel of the unit is double-layer foamed insulation board, the outer layer is $0.6 \mathrm{~mm}$ stainless steel plate, the inner layer is $0.6 \mathrm{~mm}$ Zinc steel, insulation for the polyurethane foam,, the surface rust treatment after painting to maintain good insulation properties. The test room set aside space to ensure that any part of the dehumidifier to the wall of the distance of not less than $1 \mathrm{~m}$,so that the air to maintain stability and the temperature and humidity uniformity.

The dehumidifier itself has a number of factors that will affect the accuracy of the test, because the actual situation a small amount of air will avoid in the evaporator cooling dehumidification process from the gap between the evaporator and condenser through, which led to the actual measurement of air volume is higher than the actual treatment of the air flow.

Dehumidifier sealing must also carry out the necessary inspection, In the normal refrigerant charge,less than $15 \mathrm{~kg} /$ hdehumidifier with a sensitivity of $1 \times 10^{-6} \mathrm{~Pa} \cdot \mathrm{m}^{3} / \mathrm{sleak}$ detector, more than $15 \mathrm{~kg} /$ hdehumidifier with a sensitivity of $1 \times 10^{-6} \mathrm{~Pa} \cdot \mathrm{m}^{3} / \mathrm{sleak}$ detector.In accordance with the relevant national standards ${ }^{[5][7]}$, test equipment used in various types of measuring instruments should be consistent with a certain degree of accuracy, the corresponding measurement results should also meet certain test conditions tolerance, as is shown in Table 1.

TABLE 1.Measuring instruments and test conditions tolerance

\begin{tabular}{cccc}
\hline TEST ITEMS & $\begin{array}{c}\text { MEASURING } \\
\text { INSTRUMENTS }\end{array}$ & $\begin{array}{c}\text { INSTRUMENT } \\
\text { ATION } \\
\text { ACCURACY }\end{array}$ & $\begin{array}{c}\text { TOLERAN } \\
\text { CE OF } \\
\text { TEST } \\
\text { CONDITIO } \\
\text { NS }\end{array}$ \\
\hline DRY BULB & $\begin{array}{c}\text { Platinum resistance } \\
\text { thermometer }\end{array}$ & $\pm 0.1^{\circ} \mathrm{C}$ & $\pm 0.3^{\circ} \mathrm{C}$ \\
TEMPERATURE \\
WET BULB & $\begin{array}{c}\text { Platinum resistance } \\
\text { thermometer }\end{array}$ & $\pm 0.1^{\circ} \mathrm{C}$ & $\pm 0.2^{\circ} \mathrm{C}$ \\
TEMPERATURE & $\begin{array}{c}\text { Platinum resistance } \\
\text { WATER }\end{array}$ & $\pm 0.1^{\circ} \mathrm{C}$ & $\pm 0.2^{\circ} \mathrm{C}$ \\
$\begin{array}{c}\text { TEMPERATURE } \\
\text { THE WIND } \\
\text { STATIC }\end{array}$ & $\begin{array}{c}\text { Differential pressure } \\
\text { transmitter }\end{array}$ & $\pm 1.0 \%$ & - \\
PRESSURE & Flow meter & $\pm 1.0 \%$ & - \\
LIQUID FLOW & Wind tunnel & $\pm 2.5 \mathrm{~Pa}$ & - \\
RATE & AIR FLOW & &
\end{tabular}

\section{OVERALL DESIGN}

\section{1 hardware design}

The thermostat dehumidifier performance measurement device hardware part of the measurement and control system mainly includes PC, data acquisition system, S7-300 series PLC, C series programmable controller, PAC series power regulator, UT35A series digital regulator, touch screen and so on. The data acquisition system includes A-level Pt100 temperature sensor, HM series relative humidity sensor, $M$ series temperature transmitter, EJA110 series differential pressure transmitter, WT330 power meter, MX100 data acquisition device and so on. Test instruments are to meet the national standard, with high test accuracy. Test and control system communication Fieldbus technology using distributed control system, IPC through industrial Ethernet and PLC for data exchange and command transfer, PLC through the bus to the I / O control and test equipment in series as a whole, to achieve the host computer With the main station of the interaction, through the master station touch screen to achieve the equipment on and off, to monitor and adjust the working state, in order to achieve the adjustment of the test environment and 
data collection.

\section{2 software design}

The software design and development tool of the device control system is Visual Basic 6.0, which is a structured,modular,object-oriented,high-level programming language for visualization that facilitates development environments and event-driven mechanisms that run on the Windows platform.Monitoring and control software equipment monitoring interface is shown in Fig.3.The monitoring and control system software includes the following functions:

(1) system login

The system detects the IPC and the controller at startup, whether the data acquisition module to establish normal communication for the follow-up work to establish the basis for data exchange. You can also set the login password according to the degree of confidentiality of the experiment to prevent others from fraudulent use.

(2) system platform

According to the actual need to set parameters on development of human-computer interaction interface, Real-time display device operation and measurement of measured values,and can be dynamic curve in the form of its display.

(3) data experiments

The measured values can be re-processed to give useful results. For example, by analyzing and calculating the data of each measuring point, we can get the quantity of heat exchange, dehumidification and unit power dehumidification.

(4) The results print

After the end of the test results of the test data to print the form of the report; the required parameters to generate the experimental curve and print, and you can select the curve color, style and so on.

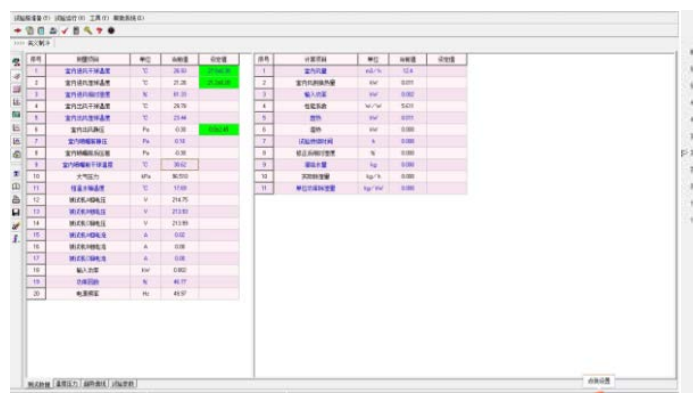

(a)

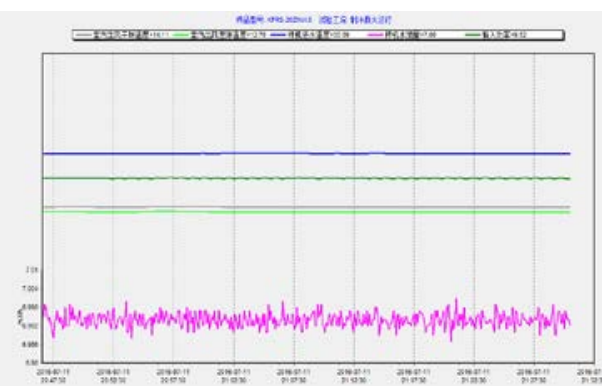

(b)

FIGURE3.System software interface diagram
(a)Test environment parameter control interface
(b)Real-time curve interface

\section{EXPERIMENTAL RESULTS}

After the completion of the performance test device for thermostat dehumidifier based on air enthalpy contrast method of wind tunnel,The test prototype(KFRS-20ZM/AS type dehumidifier produced by Shen ling Company) were tested in the nominal condition $\left(27^{\circ} \mathrm{C}, 21.2^{\circ} \mathrm{C}\right)$ several times, and with a standard air-conditioned form of laboratory test results were compared, the experimental data shown in Table 2. It can be seen that the experimental device and the standard laboratory test results in the allowable range, the test results are better to meet the design requirements, performance testing of temperature and humidity dehumidifier has a strong practicality. 
TABLE 2.Feasibility verification data of the performance test equipment under the nominal conditions

\begin{tabular}{|c|c|c|c|c|c|c|c|c|c|c|c|c|}
\hline \multirow{3}{*}{$\begin{array}{c}\text { TEST } \\
\text { CONTRAST } \\
\\
\text { THE TEST }\end{array}$} & \multicolumn{12}{|c|}{ PERFORMANCE TEST PARAMETERS } \\
\hline & \multicolumn{4}{|c|}{$\begin{array}{l}\text { DEHUMIDIFICATION } \\
\text { CAPACITY } /(\mathrm{kg} / \mathrm{h})\end{array}$} & \multicolumn{4}{|c|}{ INPUT POWER /kW } & \multicolumn{4}{|c|}{ SMER/(kg/(h·kW)) } \\
\hline & No1 & No2 & No3 & $\begin{array}{c}\text { averag } \\
\text { e }\end{array}$ & No1 & No2 & $\begin{array}{c}\text { No } \\
3\end{array}$ & $\begin{array}{c}\text { averag } \\
\mathrm{e}\end{array}$ & $\begin{array}{c}\text { No } \\
1\end{array}$ & No2 & No3 & $\begin{array}{l}\text { averag } \\
\mathrm{e}\end{array}$ \\
\hline DEVICE & $\begin{array}{c}19.2 \\
8\end{array}$ & $\begin{array}{c}19.27 \\
5\end{array}$ & $\begin{array}{c}19.2 \\
6\end{array}$ & 19.272 & $\begin{array}{c}9.51 \\
4\end{array}$ & $\begin{array}{c}9.53 \\
4\end{array}$ & $\begin{array}{c}9.5 \\
2\end{array}$ & 9.523 & $\begin{array}{c}1.8 \\
4\end{array}$ & $\begin{array}{c}1.85 \\
5\end{array}$ & $\begin{array}{c}1.86 \\
2\end{array}$ & 1.852 \\
\hline $\begin{array}{c}\text { STANDARD } \\
\text { LABORATOR } \\
\text { Y }\end{array}$ & \multicolumn{4}{|c|}{19.42} & \multicolumn{4}{|c|}{10.066} & \multicolumn{4}{|c|}{1.93} \\
\hline $\begin{array}{l}\text { DEGREE OF } \\
\text { DIFFERENCE }\end{array}$ & \multicolumn{4}{|c|}{$0.77 \%$} & \multicolumn{4}{|c|}{$5.40 \%$} & \multicolumn{4}{|c|}{$4 \%$} \\
\hline
\end{tabular}

Respectively,In the nominal condition $\left(27^{\circ} \mathrm{C}, 21.2^{\circ} \mathrm{C}\right)$, the low temperature conditions $\left(18{ }^{\circ} \mathrm{C}, 13.5^{\circ} \mathrm{C}\right)$ and the maximum load conditions $\left(32^{\circ} \mathrm{C}, 23^{\circ} \mathrm{C}\right)$, set the cooling water inlet temperature is $30^{\circ} \mathrm{C}$, The flow of the water is about $2 \mathrm{~m}^{3} / \mathrm{h}$ to $8 \mathrm{~m}^{3} / \mathrm{h}$ (an increase of $1 \mathrm{~m}^{3} / \mathrm{h}$ ), the temperature of the wet and dry bulb, dehumidification capacity and SMER with the cooling water Traffic changes. Among them, the flow meter with a large flow meter.

(1) In the nominal condition
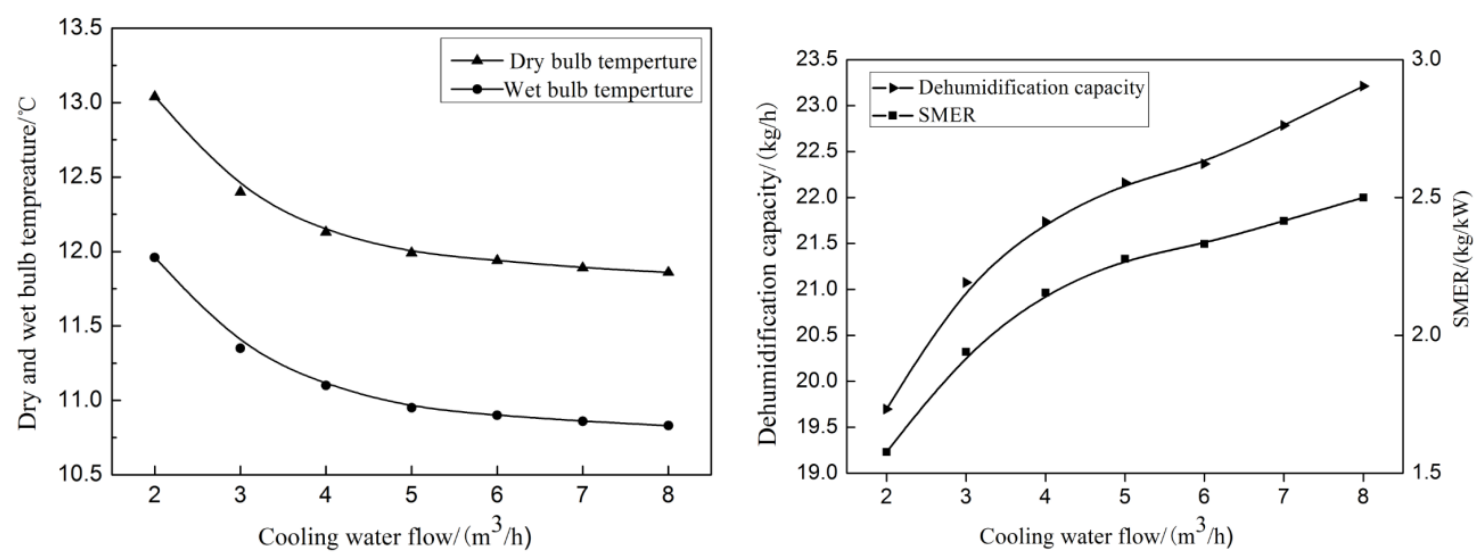

FIGURE4.The changes of dry and wet bulb temperature FIGURE5.The changes of dehumidification capacity and SMER

It can be seen from the Fig. 4 and Fig.5 that in the nominal condition the change trend of dry and wet bulb temperature is basically the same, with the cooling water flow increasing and the outlet temperature decrease. When the water is greater than $5 \mathrm{~m}^{3} / \mathrm{h}$, the curve tends to be gentle, the amount of cooling water on the impact of the temperature becomes smaller.and with the increase in cooling water flow, dehumidification and SMER are increased, while SMER in the water $5 \mathrm{~m}^{3} / \mathrm{h}$ after the growth rate decreased. 
(2) the maximum load condition
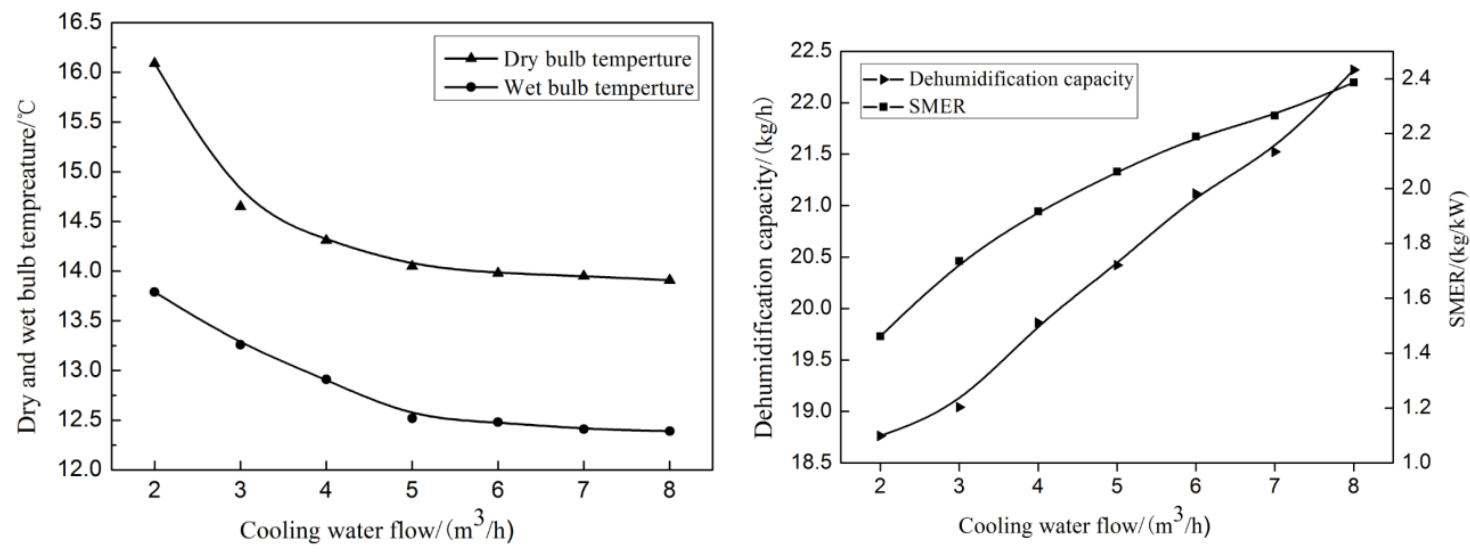

FIGURE6.The changes of dry and wet bulb temperature FIGURE7.The changes of dehumidification capacity and SMER

Can be obtained by the Fig.6 and Fig.7, with the increase of, dry and wet bulb temperature are reduced, wet and dry bulb temperature reduced speed are tending when the cooling water flow beyond $5 \mathrm{~m}^{3} / \mathrm{h}$,Similarly, with the cooling water flow increases, dehumidification capacity and SMER are increased, but the SMER growth trend gradually slowed down.

(3) the Low temperature condition
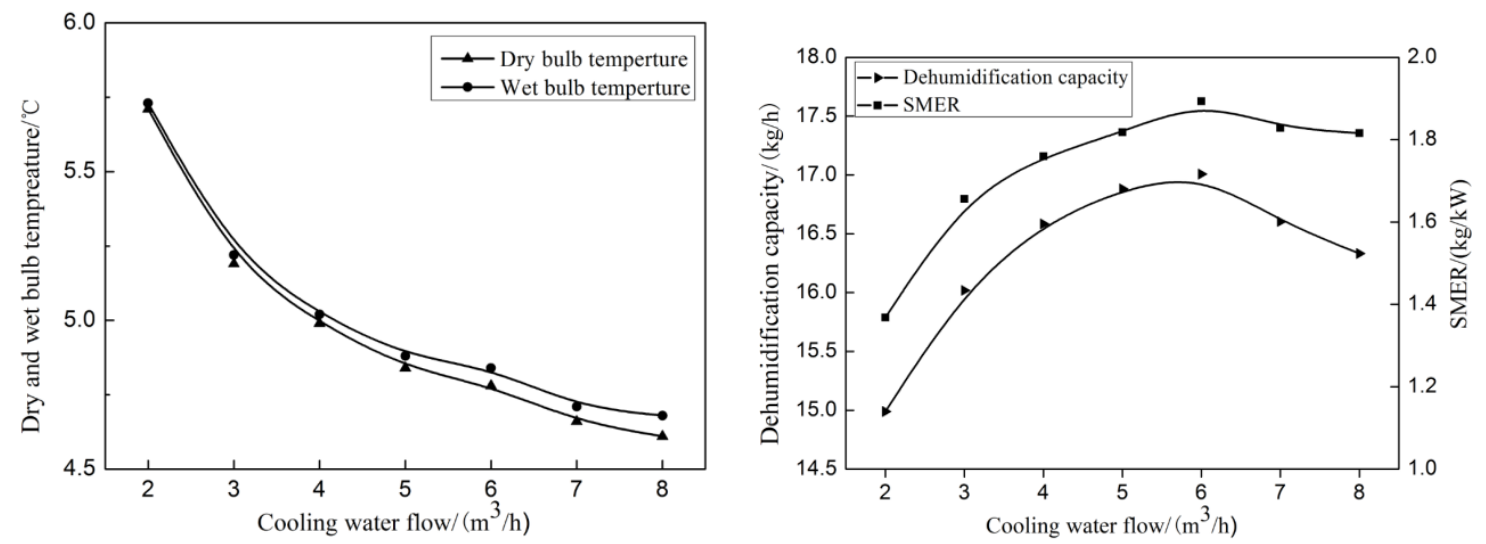

FIGURE8.The changes of dry and wet bulb temperature FIGURE9.The changes of dehumidification capacity and SMER

In the Low temperature condition, It can be seen from the Fig. 8 and Fig.9 that dry and wet bulb temperature decreased with the increase of cooling water flow. Dehumidification capacity and SMER increased fast and then decreased, the maximum amount of water at $6 \mathrm{~m}^{3} / \mathrm{h}$, which SMER maximum of $1.873 \mathrm{~kg} / \mathrm{KW}$.

Summed up the above three conditions from the energy saving, when the project dehumidification demand low air temperature, the cooling water flow is set to $5-6 \mathrm{~m}^{3} / \mathrm{h}$ the most appropriate, when the demand for high temperature, the water should be as much as possible Small, to achieve energy-saving operation.

\section{CONCLUSION}

the performance test device for thermostat dehumidifier based on air enthalpy contrast method of wind tunnel is used to test the dehumidifier in the different working conditions provided by the constant temperature and humidity testing room, for the $600-6000 \mathrm{~m}^{3} / \mathrm{h}$ requirements, and can be more accurate and perfect experimental data for the follow-up dehumidifier simulation and guide the energy-saving operation of the foundation.

According to the test data of input power, dehumidification capacity, heat transfer and SMER, the working conditions of the three working conditions of the prototype were tested by the test of the nominal conditions, the maximum load conditions and the low temperature condition. The 
relationship between dehumidification capacity and heat transfer capacity, unit power dehumidification capacity and input power was analyzed, and the reliability of the device was verified from the performance test results. At present, we should continue to improve the dehumidifier monitoring and control software to make human-computer interaction more convenient, the results show more efficient; and follow-up to the performance test device to carry out energy-saving operation of certain research.

\section{REFERENCES}

[1] Wang Hong;Wang Meixia. Discussion and Optimization of Energy Saving on Dehumidification System for Air Defense Engineering [J]. Modern Industrial Economy and Informationization,2014,7:162-165.

[2] XIA Ling,WANG Lei,WU Ya-wei, Research and Development on Air Conditioners Performance Auto Test System

[3] With Enthalpy Difference Method [J]. Power Generation \& Air Condition,2013,149:52-54.

[4] Zhuang Kepeng Miao Xiaoping Peng Fusheng. Design of performance test platform for temperature adjustable dehumidifier[J].Refrigeration and Air-Conditioning,2009,9(1):53-56.

[5] Vang Shuhua He Wei. Air enthalpy contrast method apply and study in measuring performance of the dehumidifier [J]. China Appliance Technology,2014,8:52-54.

[6] GB/T17758-1999 unitary air conditioner

[7] GB/T20109-2006 fresh air dehumidifier

[8] Li Sixiang,Liu Qiujun,Xu Zhiliang. Experimental analysis of measurement bias of airconditoner by air enthalpy difference method[J].Refrigeration and AirConditioning,2008,2(1):72-74. 